\title{
Chronic hip pain
}

\section{Danielle Dressler $^{1} \cdot$ Michael Shepel $^{1} \cdot$ Haron Obaid $^{1}$}

\section{History}

A 26 year-old male presents to the emergency department with gradually worsening right hip pain Figs. 1, 2, 3 and 4.

Below are the MRI images.

What is the diagnosis?

The diagnosis can be found at doi: 10.1007/s00256-016-2397-4

Danielle Dressler

dmd776@mail.usask.ca

1 Department of Medical Imaging, Royal University Hospital, 103 Hospital Drive, Saskatoon, SK S7N 0W8, Canada

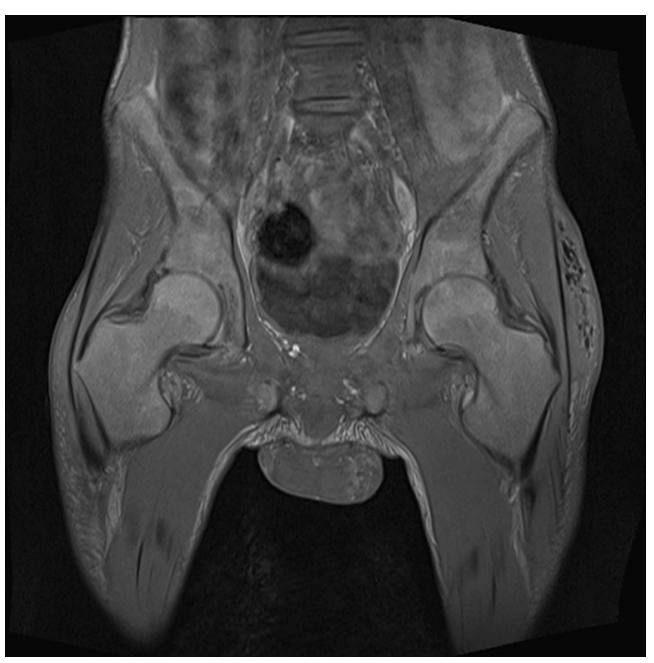

Fig. 1 Coronal T1 pelvis

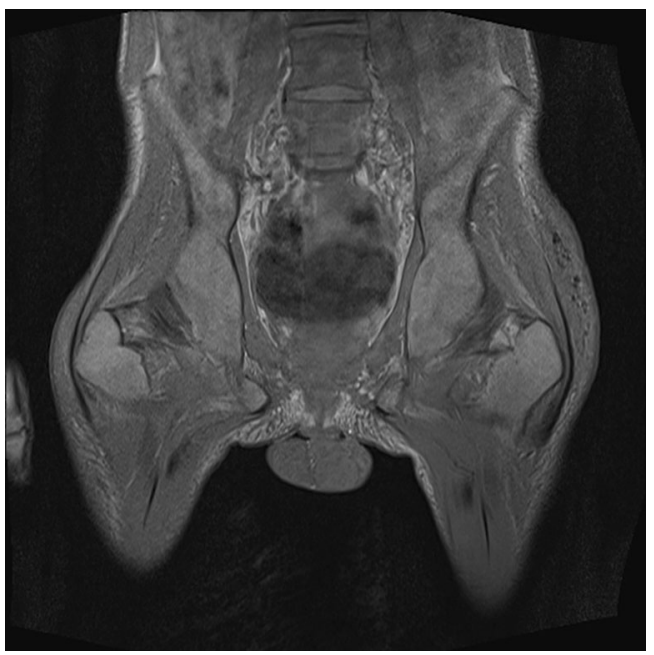

Fig. 2 Coronal T1 lumbar spine 


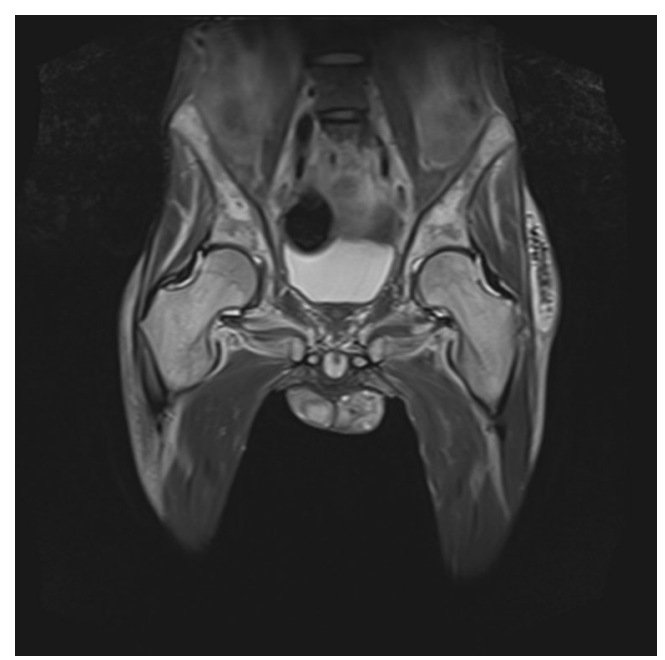

Fig. 3 Coronal short tau inversion recovery (STIR) pelvis

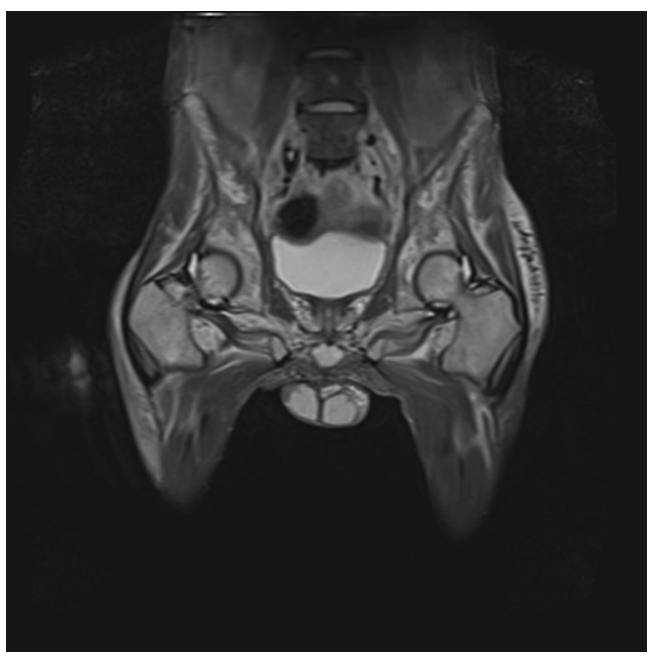

Fig. 4 Coronal short tau inversion recovery (STIR) lumbar spine 